\title{
PROBABILISTIC NONLINEAR ANALYSIS OF FAILURE OF A REACTOR HERMETIC COVER DUE TO EXTREME PRESSURE AND TEMPERATURE
}

\author{
J. Králik ${ }^{*}$, J. Králik, jr.**
}

\begin{abstract}
This paper describes the probabilistic nonlinear analysis of the reactor cover under a high internal overpressure and temperature. The scenario of a severe accident in NPP and the methodology of calculation of fragility curve of the failure overpressure using the probabilistic safety assessment PSA 2 level is presented. The model and resistance uncertainties were taken into account using the response surface method (RSM).
\end{abstract}

Keywords: nuclear power plant, reactor cover, nonlinearity, fragility curve, PSA, RSM, ANSYS

\section{Introduction}

After the accident of nuclear power plant (NPP) in Fukushimi the IAEA in Vienna adopted a large-scale project "Stress Tests of NPP", which defines some new requirements for the verification of the safety and reliability of NPP under extreme effects of internal and external environments and the technology accidents (ASME 1998, IAEA 2010). The experiences from these activities will be used to develop a methodology in the frame of project ALLEGRO, which is focused on experimental research of the reactor of 4th generation with a fast neutron core. This project is a regional (V4 Group) project of European interest. The safety documents of NRC (RG 1.2, 2009) and IAEA initiate the requirements to verify the hermetic structures of NPP loaded by two combinations of extreme actions. First extreme loads are considered for the probability of exceedance $10^{-4}$ per year and second for $10^{-2}$ per year. Other action effects are considered as the characteristic loads during the accident. In the case of the loss-of-coolant accident (LOCA) the steam pressure expands from the reactor hall to the bubble condenser (Králik, 2009). The reactor and the bubble condenser reinforced structures with steel liner are the critical structures of the NPP hermetic zone (HZ) (Králik, 2017). Another critical technology structure is the reactor hermetic cover. The previous analysis was performed for the overpressure value of $100 \mathrm{kPa}$ due to design basic accident (DBA), which corresponds to the loss of coolant accident due to guillotine cutting of the coolant pipe (Králik, 2009). ENEL Company proposes the maximum temperature in the reactor shaft equal to $1800{ }^{\circ} \mathrm{C}$ and in the containment around the reactor shaft equal to $350{ }^{\circ} \mathrm{C}$ (Králik, 2017). The possibility of the increase of temperature up to the containment failure state is considered in the scenario too. In the case of a severe accident the overpressure can be increased linearly and the internal and external temperatures are constant. Three types of scenarios were considered in the NPP hermetic zone HZ (Tab. 1).

Tab. 1: The assumed scenarios of the accidents in the hermetic zone.

\begin{tabular}{cccc}
\hline Type & Duration & Overpressure in $\mathrm{HZ}[\mathrm{kPa}]$ & Extreme internal temperatures $\left[{ }^{\circ} \mathrm{C}\right]$ \\
\hline I. & 1 hour -1 day & 150 & 127 \\
\hline II. & 2 hours -7 days & 250 & 150 \\
\hline III. & 1 year & - & $80-120$ \\
\hline
\end{tabular}

\footnotetext{
* Prof. Ing. Juraj Králik, CSc.: FCE STU Bratislava, Radlinského 11; 810 05, Bratislava; SK, juraj.kralik@ stuba.sk

** Ing. Juraj Králik, PhD.: Free Doctoral Engineer, Vígl’ašská 12; 851 07, Bratislava; SK, ing.kralikj@hotmail.com
} 
The critical one was the accident during 7 days with the overpressure $250 \mathrm{kPa}$, internal temperature $150{ }^{\circ} \mathrm{C}$ and external temperature $-28{ }^{\circ} \mathrm{C}$.

\section{Calculation model}

The technology segments of the NPP hermetic zone are made of steel. The reactor hermetic cover is shown in Fig. 1. The reactor hermetic cover is an all-welded structure consisting of a spherical and a cylindrical part. The spherical part has a manhole of $500 \mathrm{~mm}$ in diameter with a ladder. The manhole facilitates equipment maintenance in the concrete cavity without the necessity to remove the protective cover. In order to ensure higher strength of the structure (on a seismic event), the protective cover is reinforced with a pipe (inner $\varnothing 712 \mathrm{~mm}$ ) and 6 ribs. At the top, the pipe is welded in the center of the cover spherical part, while the other end covers the ring on the upper block beam. The protective cover is set on a counter-flange and is attached to it with sixty M48 bolts and sealed with packing. The cap structure includes a platform with railing.

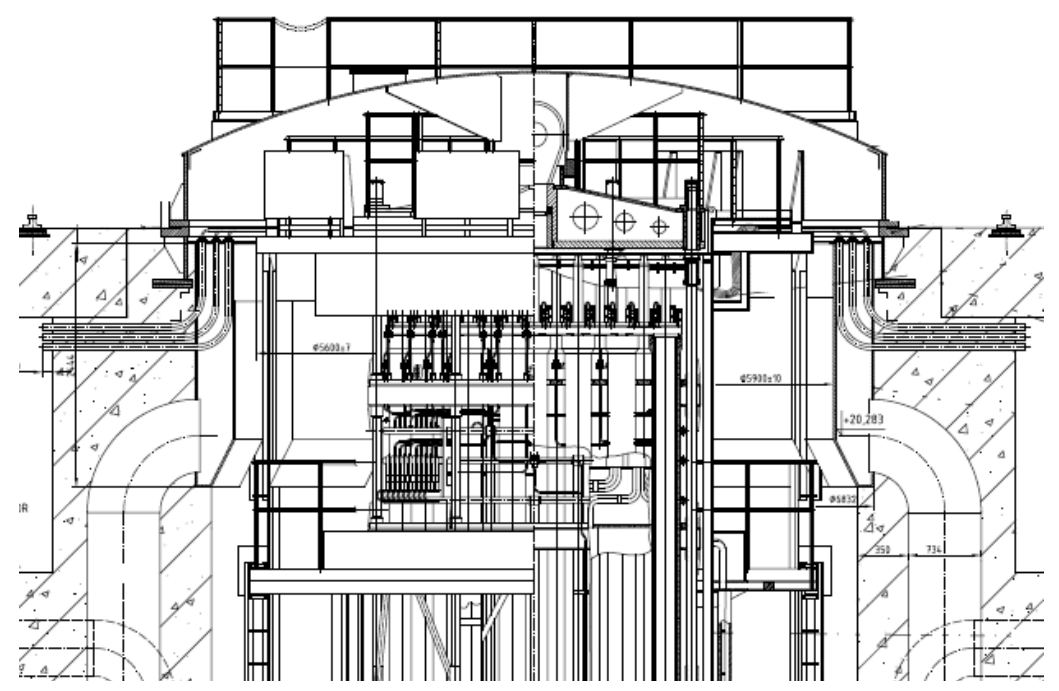

Fig. 1: Vertical section of the reactor with reactor protective cover.

The finite element model of reactor cover was created in software ANSYS using the shell, beam, combine and mass elements. The envelope of cover is modeled using layered shell elements (SHELL181). The surface load is defined using 3D structural surface elements (SURF154). The connection with bolts is modelled by combine elements (COMBINE14). The elements of point mass (MASS21) present the concentrated masses adequate to local load of the technology, beam elements (BEAM44) were used for frame and beam connection. The contact element (CE) and links (CP) were used for the joint connection. The upper part of the cover has lugs used to handle it. The FE-model (RCOV) consists of 27824 shell, beam and mass elements with 22887 nodes (Fig. 2).
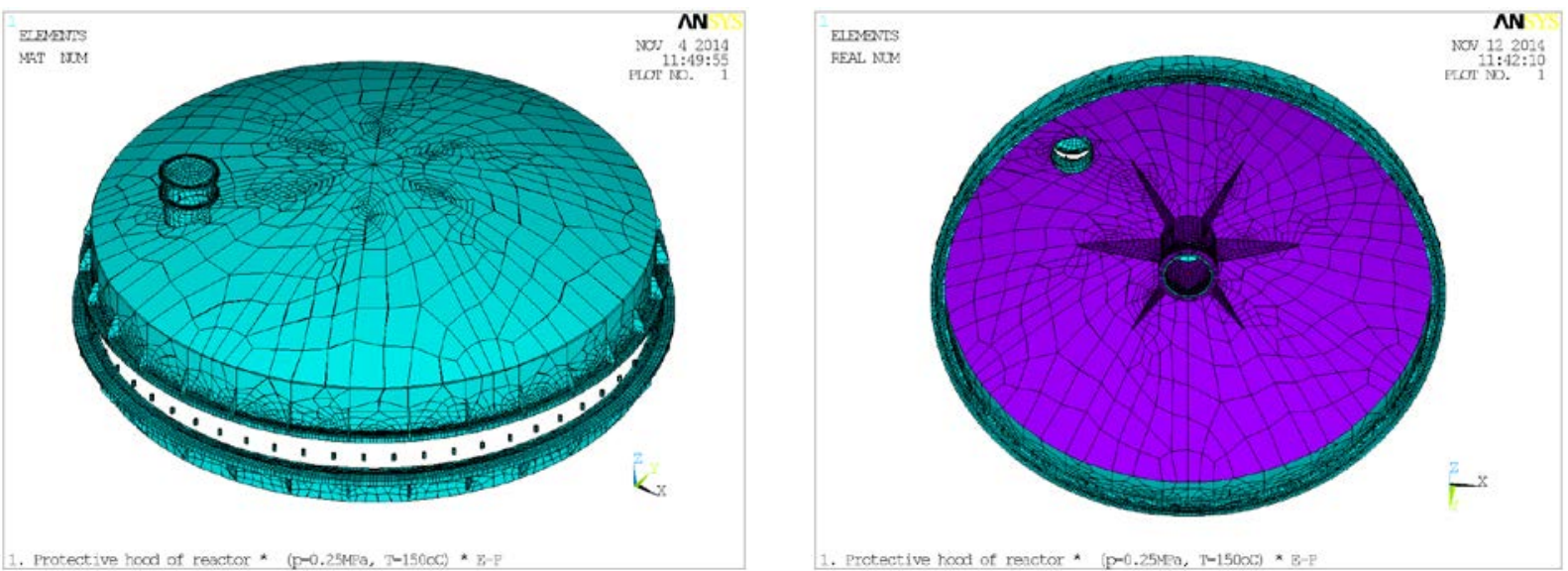

Fig. 2: FE-Model of the reactor protective cover (RCOV). 


\section{Probability nonlinear assessment}

The probability analysis of the loss of the reactor cover integrity was made for the overpressure loads from $250 \mathrm{kPa}$ to $1000 \mathrm{kPa}$ using the nonlinear solution of the static equilibrium considering the geometric and material nonlinearities of the steel shell and beam elements. The probability nonlinear analysis of the technology segments is based on the proposition that the relation between the input and output data can be approximated by the approximation function (RSM) in the form of the polynomial (Králik, 2009).

The thermal-dependent material properties were used following the input data for material 08CH18N10T defined in standards CSN 413240, CSN 411700, CSN 413230, CSN 413240 and NTD SAI Section II. The criterion for the maximum stress values is limited by the H-M-H plastic potential (Králik, 2009). The failure of the steel structure is limited by the maximum strain values or by the stability of the nonlinear solution. The standard STN EN 1993 1-2 defines following characteristic values of the strain for the structural steel - yield $\varepsilon_{a y, \theta}=0.02$ strain, ultimate $\varepsilon_{a u, \theta}=0.15$ strain, max. limit strain $\varepsilon_{a e, \theta}=0.20 \quad$ (see Fig. 3).

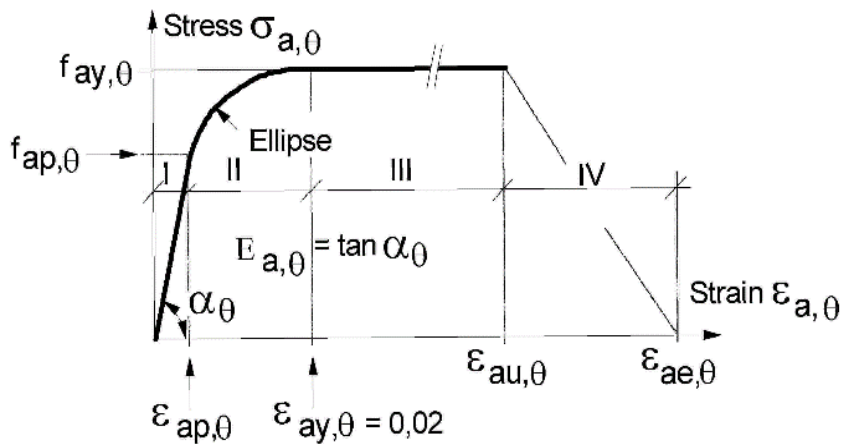

Fig. 3: Stress-strain relationship of the steel dependent on temperature (HANDBOOK 5, 2005)

\section{Uncertainties of the input data}

The uncertainties were taken from the following sources (HANDBOOK 5, 2005):

- Parameters of material properties. Based on experiments with concrete elements the coefficient of variation is $11.1 \%$. In case of other materials this value is about $5 \%$.

- Assessment of mechanical characteristics error factors are about $8-12 \%$, it depends on the construction material differences used for the different units with VVER 440/213. In some cases, it can be conservative, in other cases non-conservative impact.

- Uncertainties in the numerical results in the value of $10-15 \%$. In this area we can take into consideration the steel liner with the concrete elements.

2 Uncertainties arising from the temperature effects in the value of $10 \%$.

O Other calculations assumptions 3-5\%.

Tab. 2: Variability of input parameters.

\begin{tabular}{|c|c|c|c|c|c|c|c|}
\hline Quantity & $\begin{array}{c}\text { Charact. } \\
\text { value }\end{array}$ & Variable & $\begin{array}{c}\text { Histog. } \\
\text { type }\end{array}$ & $\begin{array}{c}\text { Mean } \\
\mu\end{array}$ & $\begin{array}{l}\text { Coeff. of } \\
\text { Var. [\%] }\end{array}$ & $\begin{array}{c}\text { Minim. } \\
\text { value }\end{array}$ & $\begin{array}{c}\text { Maxim. } \\
\text { value }\end{array}$ \\
\hline \multicolumn{8}{|c|}{ Material } \\
\hline Strength & $F_{\mathrm{k}}$ & $f_{\text {var }}$ & $N$ & 1.1 & 6.6 & 0.774 & 1.346 \\
\hline \multicolumn{8}{|c|}{ Action effects } \\
\hline Dead load & $G_{\mathrm{k}}$ & $g_{\mathrm{var}}$ & $N$ & 1 & 5 & 0.808 & 1.195 \\
\hline Live load & $Q_{\mathrm{k}}$ & $q_{\mathrm{var}}$ & $G U$ & 0.643 & 22.6 & 0.232 & 1.358 \\
\hline Pressure LOCA & $p_{\mathrm{k}}$ & $p_{\mathrm{var}}$ & $N$ & 1 & 8 & 0.698 & 1.333 \\
\hline Temperature & $T_{\mathrm{k}}$ & $t_{\mathrm{var}}$ & $G U$ & 0.667 & 14.2 & 0.402 & 1.147 \\
\hline \multicolumn{8}{|c|}{ Model uncertainties } \\
\hline Action & $E_{\mathrm{k}}$ & $e_{\mathrm{var}}$ & $N$ & 1 & 5 & 0.813 & 1.190 \\
\hline Resistance & $R_{\mathrm{k}}$ & $r_{\mathrm{var}}$ & $N$ & 1 & 5 & 0.812 & 1.201 \\
\hline
\end{tabular}

The mean values and standard deviations were defined in accordance with the experimental test and design values of the material properties and the action effects (see Tab. 2). Based on the results from the 
simulated nonlinear analysis of the technology segments and the variability of the input parameters, $10^{6}$ Monte Carlo simulations were performed in the system ANSYS.

\section{Fragility curves of failure pressure}

The probability of reactor cover failure is calculated from the probability of the reliability function $R F$ in the form

$$
P_{f}=P(R F<0), \quad R F=1-\varepsilon_{e f} / \varepsilon_{a y, \theta}
$$

where the reliability condition $R F$ is defined depending on a concrete failure condition. The fragility curve of the failure pressure (see Fig. 4) was determined using 45 probabilistic simulations using the RSM approximation method with the experimental design

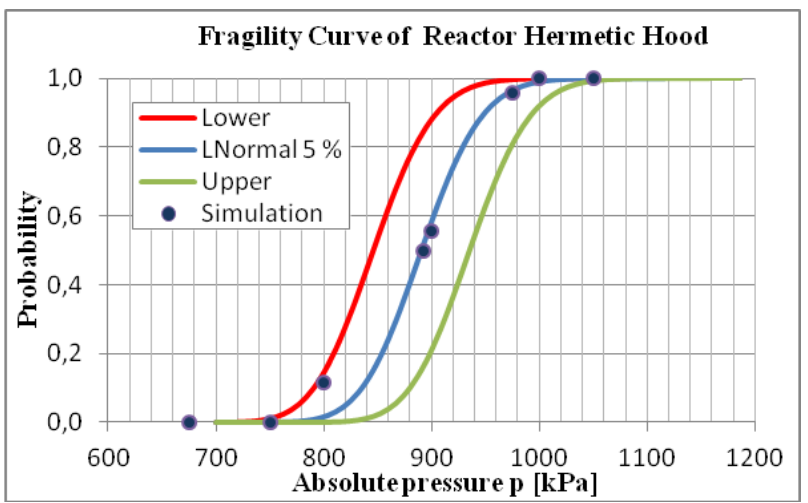

Fig. 4: Fragility curves of the reactor protective cover for normal distribution with 5\% envelope

\section{Conclusions}

The probability analysis of the loss of the concrete containment integrity was made for the overpressure loads from $250 \mathrm{kPa}$ to $1000 \mathrm{kPa}$ using the nonlinear solution of the static equilibrium. The uncertainties of the loads level (temperature, dead and live loads), the material model of the steel structures as well as the inaccuracy of the calculation model and the numerical methods (Králik, 2009, 2017) were taken into account in the approximation RSM method for CCD experimental design and $10^{6}$ Monte Carlo simulations. The critical technology segment of the containment is the reactor protective cover with the failure pressure $\mathrm{p}_{\mathrm{u} .0 .05}=766.9 \mathrm{kPa}$. The mean value of pressure capacity of the reactor protective cover is $\mathrm{p}_{\mathrm{u} .0 .50}=891.8 \mathrm{kPa}$. Upper bound of failure pressure for $95 \%$ probability of exceedance is $\mathrm{p}_{\mathrm{u} .0 .95}=973.6$ $\mathrm{kPa}$.

\section{Acknowledgement}

The article was written with the financial support of the Grant Agency of Slovak Republic (Registration Number VEGA 1/0265/16).

\section{References}

ASME Boiler and Pressure Vessel Code (1998), Section III, Div. 1, Appendix F, "Rules for Evaluation of Service Loadings with Level D Service Limits,” American Society of Mechanical Engineers.

HANDBOOK 5 (2005) Implementation of Eurocodes Reliability Backgrounds. Design of Buildings for the Fire Situation. Development of Skills Facilitating Implementation of Eurocodes. Leonardo Da Vinci Pilot Project CZ/02/B/F/PP-134007. Prague, CR.

IAEA Safety Series No. SSG-4 (2010) Development and Application of Level 2 Probabilistic Safety Assessment for Nuclear Power Plants, Vienna.

Králik, J. (2009) Safety and Reliability of Nuclear Power Buildings in Slovakia. Earthquake-Impact-Explosion. Ed. STU Bratislava, 307 pp. ISBN 978-80-227-3112-6.

Králik, J. (2017) Risk Assessment of NPP Safety in Case of Emergency Situations on Technology, In: Monograph "Recent Improvements of Power Plants Management and Technology", Ed. Nikolic, A. B. Janda, Z. S. Pp. 6996, Pub. INTECH, ISBN 978-953-51-3357-5.

NRC, RG 1.200 (2009) An Approach for Determining the Technical Adequacy of Probabilistic Risk Assessment Results for Risk-Informed Activities, U.S. Nuclear Regulatory Commission, Washington, DC. 